\title{
Investigation on Zinc Selenide and Copper Selenide Thin Films Produced by Chemical Bath Deposition
}

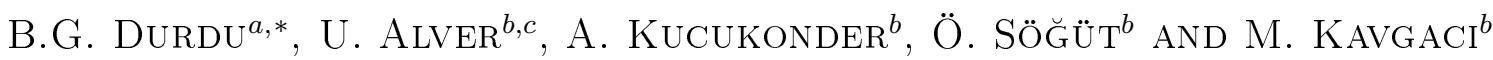 \\ ${ }^{a}$ Kilis 7 Aralik University, Vacational Higher School of Health Services, Opticianry Program \\ 79000, Kilis, Turkey \\ ${ }^{b}$ Kahramanmaras Sütcü Imam University, Faculty of Science and Letters, Department of Physics \\ 46100, K. Maraş, Turkey \\ ${ }^{c}$ International University of Sarajevo, Department of Electrical and Electronics Engineering \\ 71210, Sarajevo, Bosnia and Herzegovina
}

(Received December 7, 2012; in final form March 27, 2013)

The zinc selenide and copper selenide thin films were deposited by chemical deposition technique on glass substrates. For both films, sodium selenosulphate was used as a selenide ion source in an alkaline solution. The $\mathrm{X}$-ray diffraction patterns show that the $\mathrm{ZnSe}$ has a cubic structure and $\mathrm{Cu}_{3} \mathrm{Se}_{2}$ film has a tetragonal structure. The relative intensity $K_{\beta} / K_{\alpha}$ of zinc and copper selenide thin films has been measured by using a ${ }^{241} \mathrm{Am}$ radioisotope source $(75 \mathrm{mCi})$. The obtained results were compared with the theoretical values.

DOI: $10.12693 /$ APhysPolA.124.41

PACS: 32.30.Rj, 78.70.En, 32.30.-r, 32.80.Fb

\section{Introduction}

Zinc selenide (ZnSe) and copper selenide, metal chalcogenide semiconductors, have been studied with great interest during the past decades because of their potential applications in the fabrication of optical devices. ZnSe is $n$-type semiconducting material with a wide direct band gap $(2.7 \mathrm{eV})$ at room temperature and is transparent over a wide range of the visible spectrum. It is a promising material for use in photovoltaic devices, blue light emitting devices and laser diodes [1-3].

On the other hand, copper selenide is also a semiconducting material, and its electrical and optical properties are suitable for many photovoltaic applications. Copper selenide is a very interesting material because it has many phases and structural forms: stoichiometric $\alpha-\mathrm{Cu}_{2} \mathrm{Se}$, $\mathrm{Cu}_{3} \mathrm{Se}_{2}, \mathrm{CuSe}$, and $\mathrm{CuSe}_{2}$, as well as non-stoichiometric, $\mathrm{Cu}_{2-x}$ Se. There are also many crystallographic forms of copper selenide thin films such as monoclinic, orthorhombic, cubic, tetragonal and hexagonal. It is also reported that $\mathrm{CuSe}$ has a hexagonal structure at room temperature and undergoes transition to an orthorhombic structure at $48^{\circ} \mathrm{C}$ and back to a hexagonal structure at $120^{\circ} \mathrm{C}$ [4-6]. CuSe has $p$-type conductivity and is useful in the solar cell application $[4,7,8]$.

Zinc and copper selenide thin films can be obtained by a variety of techniques such as vacuum evaporation, electrodeposition, solid-state reaction, cathodic deposition, selenization and chemical bath deposition (CBD)

\footnotetext{
*corresponding author; e-mail: bgokerdurdu@kilis.edu.tr, bgoker@hotmail.com
}

[6, 9-18]. Of these techniques, the chemical bath deposition is a convenient and low cost technique for the growing ZnSe and copper selenide thin films. In the literature, many different recipes exist for the growth of $\mathrm{ZnSe}$ [19-22] and copper selenide thin films [5, 16, 17, 23] by using CBD technique.

$\mathrm{X}$-ray fluorescence spectrometry (XRF) is a technique that is used in the thin film and semiconductor industry. It is a nondestructive analytical technique that is widely used for the qualitative and quantitative elemental analysis of the composition of a sample. X-ray intensities in the XRF spectra analysis are proportional to the total material amount of the respective elements in the film. The small difference in the peaks might be corresponding to possible material losses at different stage of the film processing. Detail of XRF technique has been described elsewhere [24]. Many studies have been made concerning chemical effect on $K_{\beta} / K_{\alpha}$ intensity ratios, fluorescence cross-section, fluorescence yields and mass attenuation coefficients [25-34]. Chemical effect on $K_{\beta} / K_{\alpha}$ intensity ratios of $\mathrm{Mn}, \mathrm{Ni}$ and $\mathrm{Cu}$ complexes are investigated by Çevik et al. [35]. Söğüt et al. [36] has studied alloying effect on $K_{\beta} / K_{\alpha}$ intensity ratios in $\mathrm{Cr}_{x} \mathrm{Ni}_{1-x}, \mathrm{Cr}_{x} \mathrm{Al}_{1-x}$ alloys. Measurements of $\eta_{K L}$ and $\eta_{K M}$ vacancy transfer probabilities in the same alloys were investigated by Söğüt [37]. Bacaksız and Çevik [38] have studied $K$ shell fluorescence yield of $\mathrm{Cd}$ and $\mathrm{Zn}$ in $\mathrm{Cd}_{1-x} \mathrm{Zn}_{x} \mathrm{~S}$ thin films. Kucukonder [39] has studied X-ray fluorescence cross-section for bromide and iodine compounds.

In this study, zinc and copper selenide thin films were produced by using CBD technique on the glass substrates and the relative intensity $K_{\beta} / K_{\alpha}$ of these films studied by XRF. The obtained results were compared with theoretical values. 


\section{Experimental details}

\subsection{ZnSe thin film deposition}

$\mathrm{ZnSe}$ thin films were grown on commercial microscopic glass slide with the size of $26 \times 76 \times 2 \mathrm{~mm}^{3}$ by using CBD technique. Deposition is performed in a double walled water jacket. Substrate is mounted on a plastic holder and the solution is continuously stirred at constant speed during deposition. The bath temperature was controlled with a hot plate. In order to obtain good adherence and uniformity for the film, firstly the glass substrate was cleaned with detergent, dried, degreased with acetone, etched with diluted 5\% hydrochloric acid solution and then washed with deionized water and finally dried in air. In order to obtain amount of $\mathrm{ZnSe}$ and copper selenide the glass substrates were weighed before and after deposition.

A standard procedure was followed to deposit the ZnSe films [22]. The deposition bath consists of an aqueous solution of $25 \mathrm{ml}(0.5 \mathrm{M})$ zinc chloride, $1 \mathrm{ml}$ hydrazine hydrate $(100 \%), 10 \mathrm{ml}(25 \%)$ ammonia $\left(\mathrm{NH}_{3}\right), 25 \mathrm{ml}$ sodium selenosulphate $\left(\mathrm{Na}_{2} \mathrm{SeSO}_{3}\right)$ solution and deionized water to make a total volume of $100 \mathrm{ml}$. In this study, $\mathrm{Na}_{2} \mathrm{SeSO}_{3}$ solution was used as a selenium (Se) source for the CBD process and prepared by mixing $10 \mathrm{~g}$ Se powder with $100 \mathrm{~g}$ sodium sulfide $\left(\mathrm{Na}_{2} \mathrm{SO}_{3}\right)$ in $500 \mathrm{ml}$ distilled water at $80^{\circ} \mathrm{C}$ for $10 \mathrm{~h}$ as described by Kale and Lokhande [22]. The chemical bath solution was placed in a glass beaker and controlled at $55^{\circ} \mathrm{C}$. The $\mathrm{pH}$ value of the prepared solution was adjusted during the deposition by using $\mathrm{NH}_{3}$ and kept at a value of 10-11. Film deposition starts when the $\mathrm{Na}_{2} \mathrm{SeSO}_{3}$ is added. During the deposition bath solution was stirred. The growth time was $180 \mathrm{~min}$. At the end of the deposition process the substrates were removed from the chemical bath and washed by deionized water and finally dried. The films grown on the backside of the glass substrates were removed by using 1:10 $\mathrm{HCl}$ solution. The observed film was uniform and it had very good adhesion to glass substrates, which was tested by visual inspection and scotch tape.

\subsection{Copper selenide thin film deposition}

The procedure is similar to the one used for $\mathrm{ZnSe}$. The deposition bath consists of an aqueous solution of $4 \mathrm{ml}$ $(0.5 \mathrm{M})$ copper sulfate pentahydrate $\left(\mathrm{CuSO}_{4} \cdot 5 \mathrm{H}_{2} \mathrm{O}\right), 4 \mathrm{ml}$ $(0.1 \mathrm{M})$ trisodium citrate, $1 \mathrm{ml}(0.5 \mathrm{M})$ sodium hydroxide, $4 \mathrm{ml}$ sodium selenosulphate $\left(\mathrm{Na}_{2} \mathrm{SeSO}_{3}\right)$ solution and deionized water to make a total volume of $50 \mathrm{ml}$. The deposition was carried out at room temperature $\left(20^{\circ} \mathrm{C}\right)$ and the growth time was $4 \mathrm{~h}$. The $\mathrm{pH}$ of the solution was about 8 and very slow stirring was given to the solution during the deposition. The obtained film was uniform but the adherence to the glass substrate was poor. The adherence measurement was made by scotch tape test.

\subsection{XRF measurements}

$K_{\beta} / K_{\alpha}$ intensity ratios of the $\mathrm{CuSe}$ and $\mathrm{ZnSe}$ thin films were obtained by using XRF technique. A typical experimental geometry used for XRF measurements is given elsewhere [39]. $\gamma$-rays of $59.543 \mathrm{keV}$ emitted from a ${ }^{241} \mathrm{Am}$ radioisotope source $(75 \mathrm{mCi})$ were used to excite the target atoms in the films. The characteristic $K_{\alpha}$ and $K_{\beta}$ X-ray fluorescence emitted from the samples were detected with $\mathrm{Si}(\mathrm{Li})$ detector $(\mathrm{FWHM}=155 \mathrm{eV}$ at $5.9 \mathrm{keV})$. In addition, in order to compare our results obtained from $\mathrm{CuSe}$ and $\mathrm{ZnSe}$ thin films, we have made XRF measurements for powder of $\mathrm{Cu}, \mathrm{Zn}$, Se, (thickness $34 \times 10^{-3} \mathrm{~g} \mathrm{~cm}^{-2}$ ). The purity of these powders was better than $99.9 \%$ and they were sieved for 400 mesh. During the measurements, the thin films were on the glass substrate as deposited and test powders were supported on Mylar film.

\section{Experimental and theoretical calculation for XRF measurements}

In this study the theoretical $K_{\beta} / K_{\alpha}$ intensity ratios were calculated by using the relations

$$
\begin{aligned}
& \sigma_{K \alpha}=\sigma_{K}(E) \omega_{K} F_{K \alpha}, \\
& \sigma_{K \beta}=\sigma_{K} \omega_{K} F_{K \beta},
\end{aligned}
$$

where $\sigma_{K}(E)$ is the $K$ shell photoionization cross-section at the excitation energy $E[40], \omega_{K}$ is the fluorescence yield of $K$ shell line [41], $F_{K \alpha}$ and $F_{K \beta}$ are the fractional ratio of $K_{\alpha}$ and $K_{\beta}$ X-rays, respectively. $F_{K \alpha}$ and $F_{K \beta}$ are defined as:

$$
F_{K \alpha}=\left(1+\frac{I_{K \beta}}{I_{K \alpha}}\right)^{-1}, \quad F_{K \beta}=\left(1+\frac{I_{K \alpha}}{I_{K \beta}}\right)^{-1},
$$

where $I_{K \beta} / I_{K \alpha}$ is the $K_{\beta} / K_{\alpha}$ intensity ratio of $K_{\beta}$ and $K_{\alpha}$ line. These ratios were obtained from the table published by Scofield [42]. The experimental $K_{\beta} / K_{\alpha}$ intensity ratios were evaluated using the relations

$$
\frac{I_{K \beta}}{I_{K \alpha}}=\frac{N_{K \beta}}{N_{K \alpha}} \frac{\beta_{K \alpha}}{\beta_{K \beta}} \frac{\varepsilon_{K \alpha}}{\varepsilon_{K \beta}},
$$

where $N_{K \beta} / N_{K \alpha}$ represent the ratio of the counting rates under the $K_{\beta}$ and $K_{\alpha}$ peaks, $\beta_{K \alpha} / \beta_{K \beta}$ is the ratio of the self-absorption correction factor of target and $\varepsilon_{K \alpha} / \varepsilon_{K \beta}$ is ratio of the detector efficiency values for $K_{\alpha}$ and $K_{\beta}$ $\mathrm{X}$-rays, respectively.

The self-absorption correction factor has been calculated by using the following expression:

$$
\beta_{K i}=\frac{1-\exp \left((-1)\left(\mu_{\mathrm{inc}} / \cos \phi_{1}+\mu_{\mathrm{Li}} / \cos \phi_{2}\right) t\right)}{\left(\mu_{\mathrm{inc}} / \cos \phi_{1}+\mu_{\mathrm{Li}} / \cos \phi_{2}\right) t},
$$

where $\mu_{\text {inc }}$ and $\mu_{\mathrm{Li}}$ are mass absorption coefficients at the incident photons and fluorescent $K_{i}$ X-ray energy of sample, respectively. $\phi_{1}$ and $\phi_{2}$ are the angles of incident photons and emitted X-ray with respect to the normal at the surface of the sample. We have used the mass absorption coefficients complied in a computer program WinXCOM [43]. $\varepsilon_{K \alpha}$ and $\varepsilon_{K \beta}$ values in the present experimental geometry were determined in a separate experiment targets having areas of cross-section that were similar to those used in the main experiment but with atomic number $22 \leq Z \leq 38$, emitting fluorescent X-rays in the energy range $4.508-14.142 \mathrm{keV}$ were irradiated in the same geometry and fluorescent X-rays were counted. 
The effective overall detection efficiency for the present geometry was determined by the following relation:

$$
I_{0} G \varepsilon_{K i}=\frac{N_{K \alpha}}{\sigma_{K \alpha} \beta_{K \alpha} t},
$$

where $N_{K \alpha}$ is the number of $K_{\alpha}$ X-rays recorded under the $K_{\alpha}$ peak, $\sigma_{K \alpha}$ is the fluorescence cross-section. The values of $K \mathrm{X}$-ray fluorescence cross-sections, $\beta_{K \alpha}$ is the self-absorption correction factor, $t$ is the thickness of target. The value of $\sigma_{K \alpha}$ is determined by using Eq. (1).

\section{Results and discussion}

The crystallinity of the film was examined by XRD using a Philips PANalytical X'Pert Pro X-ray diffractometer with $\mathrm{Cu} K_{\alpha}$ radiation $(\lambda=1.5418 \AA)$. The XRD patterns of $\mathrm{ZnSe}$ and copper selenide thin films obtained by CBD are shown in Fig. 1a and b, respectively. As shown in Fig. 1a ZnSe film has a very poor crystallinity. A broad and low intensity peak (111) observed at $2 \theta=27.52^{\circ}$ and this peak indicates that $\mathrm{ZnSe}$ film has a cubic structure. This and other diffraction peaks of the XRD pattern are in good agreement with PDF-2, reference code: 01-088-2345. In addition, XRD pattern of copper selenide shown in Fig. 1b is the characteristics of polycrystalline $\mathrm{Cu}_{3} \mathrm{Se}_{2}$ (PDF-2, reference code: 00-003-0343) with a tetragonal structure and for this film no sign of texturing was observed. Similar results for $\mathrm{ZnSe}$ and $\mathrm{Cu}_{3} \mathrm{Se}_{2}$ are also reported in literature $[22,23]$.

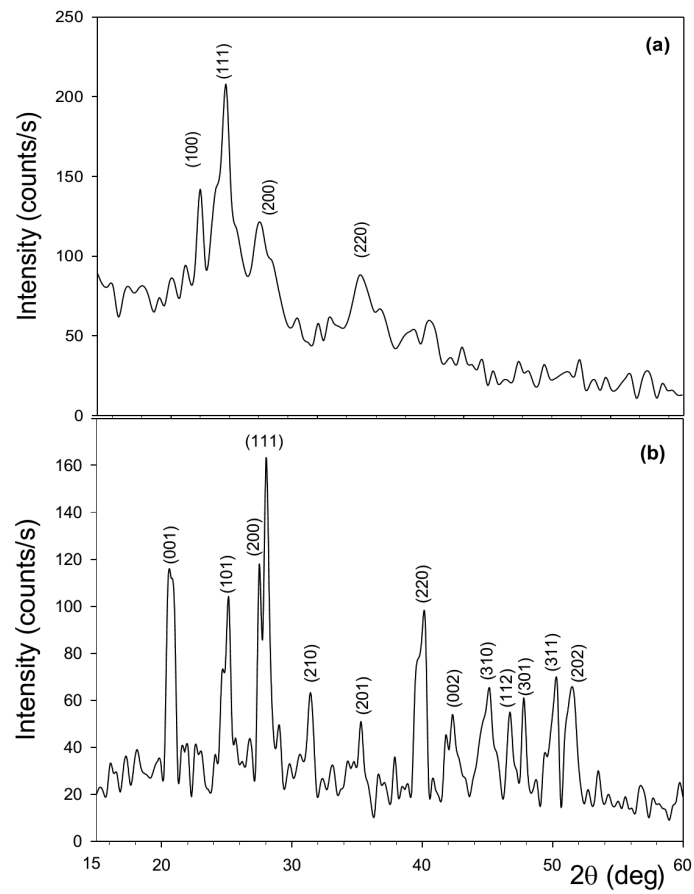

Fig. 1. XRD pattern of (a) ZnSe and (b) $\mathrm{Cu}_{3} \mathrm{Se}_{2}$ films prepared by CBD technique.

XRF spectra for $\mathrm{ZnSe}$ and $\mathrm{Cu}_{3} \mathrm{Se}_{2}$ thin films are shown in Fig. 2a and b, respectively. These spectra exhibit sev- eral different peaks corresponding to the specific channel numbers of the X-ray photons measured by the $\mathrm{Si}(\mathrm{Li})$ detector. The observed $K_{\alpha}$ and $K_{\beta}$ X-ray emission peaks of $\mathrm{Zn}, \mathrm{Cu}$ and Se elements in the film are labeled in Fig. 2. The other peaks such as elastic and Compton signals due to scattering from the entire sample and air are not shown in these figures.

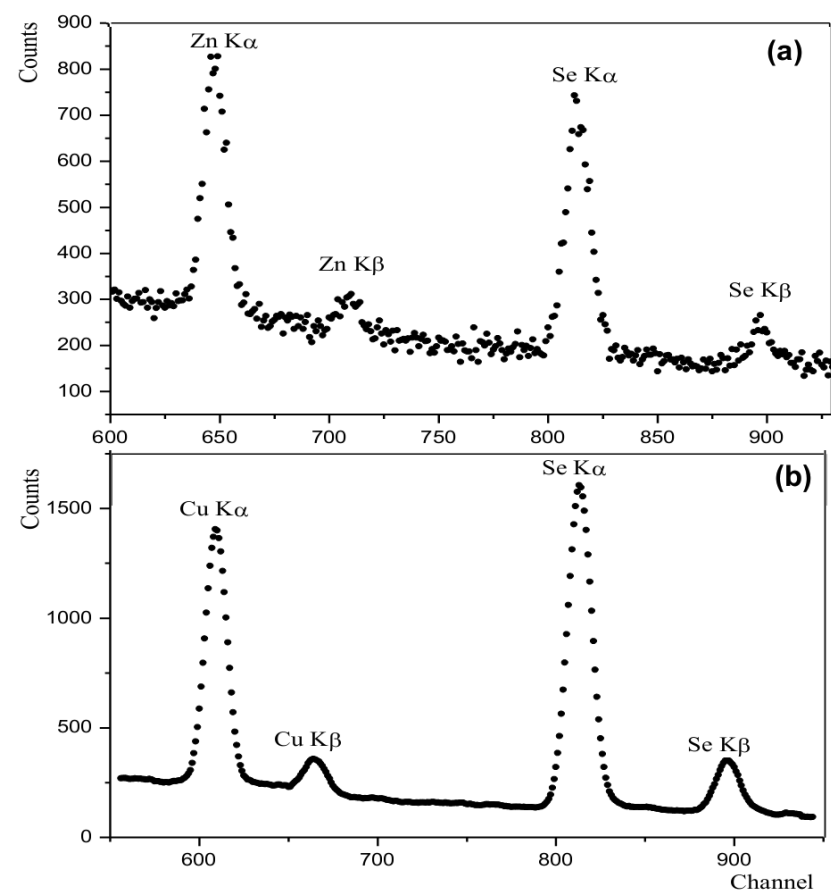

Fig. 2. Characteristic $K \mathrm{X}$-ray emission spectra of (a) $\mathrm{ZnSe}$ and (b) $\mathrm{Cu}_{3} \mathrm{Se}_{2}$ thin films.

Measured result of $K_{\beta} / K_{\alpha}$ X-ray intensity ratios for elements $\mathrm{Cu}, \mathrm{Zn}$ and Se are compared with the calculated values and other experimental values. The results and some error values are given in Table.

The overall error in present measurement is estimated to be $\approx 7 \%$. This error is the quadrature sum of the uncertainties in the different parameters used to evaluate $K$ X-rays intensity ratios, i.e. target thickness $(\approx 2 \%)$, the evaluation of the peak area $(\approx 1), I_{0} G \varepsilon$ product $(\approx$ $2 \%)$ and the absorption correction factor $(\approx 2 \%)$.

The agreement between the present experimental results and theoretical values (calculated and Scofield) predictions are within range $1-3 \%, 1-10 \%, 1-7 \%$ for $\mathrm{Cu}, \mathrm{Zn}$ and Se, respectively. In addition to this, the experimental values agree to within range $3-7 \%, 1-17 \%$ and $2-15 \%$ experimental values of Ertuğrul et al. [44], Hansen et al. [45] and Khan and Karimi [46], respectively.

The physical state and chemical combination of elements affect the characteristic X-rays. It is well known experimentally and theoretically that $K_{\beta} / K_{\alpha}$ X-ray intensity ratios in $3 d$ elements depend on the chemical environment and excitation mode [25-37]. In early studies, the influence of chemical effects has shown differences in $K_{\beta} / K_{\alpha}$ X-ray intensity ratios up to $10 \%$. Such chemi- 
cal effect can be caused either by a varying $3 d$ electron population or by the admixture of $3 p$ states from the ligand atoms to the $3 d$ states of metal or both. This effect observed in alloys and thin films is considered in accordance with electronegativity of elements being in the structure alloys and thin films [36, 37]. In that, especially in transition metals depending on electronegativity of the elements it is considered electron transfer among the $3 d$ states of the atoms. In fact, anything that alters the $3 d$ wave function can alter the ratio, such as a change in the $3 d$ electron population and the number of ligand atoms. The change of the $3 d$ electron population of the transition metal atom in the chemical compound modifies $3 p$ orbitals of the atom stronger than $2 p$ orbitals, which must be followed by a change of the $K_{\beta} / K_{\alpha}$ X-ray intensity ratios of the metal atoms in the compound. But, because our films consist of only one sample it is difficult to say whether there is a chemical effect mentioned above or not. In this type studies, in order to investigate chemical effect at least there are three different samples. In our study, the changes in intensity ratios are inside the boundaries of error and these boundaries of error are in agreement with the literature [44-46].

\section{TABLE}

Experimental and theoretical $K_{\beta} / K_{\alpha}$ X-ray intensity ratios for $\mathrm{Cu}, \mathrm{Zn}$ and $\mathrm{Se}$ compounds.

\begin{tabular}{c|c|c|c|c|c|c}
\hline \hline \multirow{2}{*}{ Samples } & \multicolumn{5}{|c|}{ Experimental } & \multicolumn{2}{|c}{ Theoretical } \\
\cline { 2 - 7 } & Present & $\begin{array}{c}\text { Ertuğrul } \\
\text { et al. [44] }\end{array}$ & $\begin{array}{c}\text { Hansen } \\
\text { et al. [45] }\end{array}$ & $\begin{array}{c}\text { Khan } \\
\text { et al. [46] }\end{array}$ & Present & $\begin{array}{c}\text { Scofield } \\
{[42]}\end{array}$ \\
\hline $\mathrm{Cu}$ & $0.125 \pm 0.005$ & 0.134 & 0.1339 & 0.137 & 0.122 & 0.1216 \\
$\mathrm{Cu}_{3} \mathrm{Se}_{2}$ & $0.121^{a} \pm 0.005$ & & & & & \\
$\mathrm{Zn}$ & $0.125 \pm 0.002$ & 0.136 & 0.1352 & 0.139 & 0.124 & 0.1241 \\
$\mathrm{ZnSe}$ & $0.111^{b} \pm 0.009$ & & & & & \\
$34-\mathrm{Se}$ & $0.140 \pm 0.004$ & 0.157 & 0.1511 & 0.161 & 0.142 & 0.1425 \\
$\mathrm{Cu}_{3} \mathrm{Se}{ }_{2}$ & $0.152^{c} \pm 0.009$ & & & & & \\
$\mathrm{ZnSe}$ & $0.137^{c} \pm 0.005$ & & & & & \\
\hline${ }^{a}$ for Cu, ${ }^{b}$ for $\mathrm{Zn},{ }^{c}$ for Se
\end{tabular}

\section{Conclusion}

The $\mathrm{ZnSe}$ and $\mathrm{Cu}_{3} \mathrm{Se}_{2}$ thin films were prepared by chemical deposition technique on glass substrates. The XRD patterns show that the ZnSe has a cubic structure and $\mathrm{Cu}_{3} \mathrm{Se}_{2}$ film has a tetragonal structure known as umangite. $K_{\beta} / K_{\alpha}$ intensity ratio was studied for these films and the obtained results were compared with the theoretical values.

\section{Acknowledgments}

This work was supported by Scientific Research Fund of Kahramanmaras Sütcü Imam University, Turkey (project No. 2005/2-28).

\section{References}

[1] R.J. Robinson, Z.K. Kun, Appl. Phys. Lett. 27, 74 (1975).

[2] S. Fujita, H. Mimoto, T. Noguchi, J. Appl. Phys. 50, 1079 (1979).

[3] G.F. Neumark, R.M. Mark, J. Depuyat, Phys. Today 47, 26 (1994).

[4] S.K. Haram, K.S.V. Santhanam, M. Numannspallart, C. Levyclement, Mater. Res. Soc. Bull. 27, 1185 (1992).
[5] V.M. Gracia, P.K. Nair, M.T.S. Nair, J. Cryst. Growth 203, 113 (1999).

[6] M. Lakshmi, K. Bindu, S. Bini, K.P. Vijayakumar, C.S. Kartha, T. Abe, Y. Kashiwaba, Thin Solid Films 386, 127 (2001).

[7] H. Okimura, T. Matsumae, R. Makabe, Thin Solid Films 71, 53 (1980).

[8] W.S. Chen, J.M. Stewart, R.A. Mickelsen, Appl. Phys. Lett. 46, 1095 (1985).

[9] G.K. Padam, Thin Solid Films 150, 89 (1987).

[10] A.M. Hermann, L. Fabick, J. Cryst. Growth. 61 , 658 (1983).

[11] D. Lippkow, H.H. Strehblow, Electrochem. Acta 43, 2131 (1998).

[12] C. Kaito, A. Nonaka, S. Kimura, N. Suzuki, Y. Saito, J. Cryst. Growth 186, 386 (1998).

[13] R.N. O'Brien, K.S.V. Santhanam, J. Electrochem. Soc. 139, 434 (1992).

[14] S. Massaccesi, S. Sanchez, J. Vedel, J. Electrochem. Soc. 140, 2540 (1993).

[15] K. Yamamoto, S. Kashida, J. Solid State Chem. 93, 202 (1991).

[16] M. Dhanam, P.K. Manoj, R.R. Prabhu, J. Cryst. Growth 280, 425 (2005). 
[17] M. Lakshmi, K. Bindhu, S. Bini, K.P. Vijayakumar, C.S. Kartha, T. Abe, Y. Kashiwaba, Thin Solid Films 370, 89 (2000).

[18] P.K. Nair, M.T.S. Nair, V.M. Gracia, O.L. Arenas, Y. Pena, A. Castillo, I.T. Ayala, O. Gomezdaza, A. Sanchez, J. Campos, H. Hu, R. Suarez, M.E. Rincon, Sol. Energ. Mater. Sol. Cells. 52, 313 (1998).

[19] C.D. Lokhande, P.S. Patil, A. Ennaoui, H. Tributsch, Appl. Surf. Sci. 123, 294 (1998).

[20] A.M. Chaparro, C. Maffiotte, M.T. Gutiérrez, J. Herrero, Thin Solid Films 358, 22 (2000).

[21] J.M. Dona, J. Herrero, J. Electrochem. Soc. 142 , 764 (1995).

[22] R.B. Kale, C.D. Lokhande, Appl. Surf. Sci. 252, 929 (2005).

[23] B. Pejova, I. Grozdanov, Solid State Chem. 158, 49 (2001).

[24] R.E. van Grieken, A.A. Markowicz, Hand Book of X-ray Spectrometry, Marcel Dekker, New York 1993.

[25] V. Aylıkcı, E. Tıraşoğlu, G. Apaydın, N. Kaya, E. Cengiz, Phys. Scr. 76, 31 (2007).

[26] S. Raj, H.C. Padhi, M. Polasik, Nucl. Instrum. Methods Phys. Res. B 160, 443 (2000).

[27] S. Raj, H.C. Padhi, M. Polasik, Nucl. Instrum. Methods Phys. Res. B 155, 143 (1999).

[28] F. Pawlowski, M. Polasik, S. Raj, H.C. Padhi, D.K. Basa, Nucl. Instrum. Methods Phys. Res. B 195, 367 (2002).

[29] Ö. Söğüt, E. Baydas, S. Seven, E. Büyükkasap, A. Kucukonder, Spectrochim. Acta B 56, 1367 (2001).

[30] Ö. Söğüt, S. Çolak, E. Büyükkasap, A. Kucukonder, J. Radioanal. Nucl. Chem. 251, 135 (2002).

[31] Ö. Söğüt, E. Büyükkasap, H. Erdoğan, Radiat. Phys. Chem. 64, 343 (2002).
[32] A. Kucukonder, Ö. Söğüt, E. Büyükkasap, E. Kucukonder, H. Çam, X-ray Spectrom. 32, 60 (2003).

[33] A. Kucukonder, Ö. Söğüt, F. Sumbul, E. Büyükkasap, J. Radioanal. Nucl. Chem. 270, 695 (2006).

[34] E. Tıraşoğlu, Ö. Söğüt, A. Tekbıyık, G. Apaydın, B. Ertuğral, J. Quant. Spectrosc. Radiat. Transfer 103, 275 (2007).

[35] U. Çevik, I. Değirmenci, B. Ertuğrul, G. Apaydın, H. Balta, Eur. Phys. J. D 36, 29 (2005).

[36] Ö. Söğüt, E. Büyükkasap, A. Kucukonder, M. Ertuğrul, Ö. Simşek, Appl. Spectrosc. Rev. 30, 175 (1995).

[37] Ö. Söğüt, Phys. Scr. 73, 466 (2006).

[38] E. Bacaksız, U. Çevik, Chem. Phys. Lett. 437, 132 (2006).

[39] A. Kucukonder, Eur. Phys. J. D 17, 293 (2001).

[40] J.H. Scofield, Theoretical Photoionization Cross Section from $1 \mathrm{keV}$ to $1500 \mathrm{keV}$, Lawrence Livermore Laboratory, UCRL 51326 Livermore, California 1973.

[41] J.H. Hubbell, P.N. Trehan, N. Sing, B. Chand, D. Mehta, M.L. Garg, R.R. Garg, S. Singh, S. Puri, J. Phys. Chem. Ref. Data 23, 339 (1994).

[42] J.H. Scofield, At. Data Nucl. Data Tables 14, 121 (1974).

[43] L. Gerward, N. Guilbert, K.B. Jensen, H. Levring, Radial. Phys. Chem. 71, 653 (2004).

[44] M. Ertuğrul, Ö. Söğüt, Ö. Şimşek, E. Büyükkasap, J. Phys. B At. Mol. Opt. Phys. 34, 909 (2001).

[45] J.S. Hansen, H.U. Freund, R.W. Fink, Nucl. Phys. A 142, 604 (1970).

[46] M.R. Khan, M. Karimi, X-ray Spectrom. 9, 32 (1980). 